\title{
Malaria's watershed
}

\author{
Malaria's moment has come, but success in control, let alone eradication, demands a renewed \\ commitment to basic research.
}

$\Lambda$ Global Malaria Action Plan, announced at the UN Millennium Development Goals Malaria Summit in New York on 25 September, has the ambitious goals of both reducing the malaria burden and eradicating the disease entirely.

Eradication any time soon might seem hopelessly optimistic, given the failure so far to make a serious dent in the number of malaria deaths. But much of the 274-page plan makes good sense. It calls for scaling up the use of existing tools, such as bednets, drugs and spraying, to near universal coverage, and then sustaining this effort for decades. True, this won't come cheaply. Funds for control have already grown from US $\$ 250$ million annually in 2004 to an estimated US $\$ 1.1$ billion this year; the plan calls for increasing that to $\$ 5$ billion annually until at least 2020. Likewise, total spending on malaria-related research has risen from \$265 million in 2003 to $\$ 422$ million in 2007; the plan would see that figure double to between $\$ 750$ million and \$900 million annually until 2018 . Whether donors will rise to the challenge is a big question, given current economic woes. Still, it is heartening that at the summit, donors from governments, industry and philanthropic organizations pledged US $\$ 3$ billion.

Striking the right balance between basic and applied research is also critical. For example, the sequencing in 2002 of the genome of Plasmodium falciparum, the main parasite that causes malaria, has stimulated the hunt for new drug and vaccine candidates. This week's issue of Nature sees the addition of two more parasite sequences: $P$. vivax, which is less deadly than P. falciparum, and P. knowlesi, which mainly infects monkeys (pages 751, 757 and 799). These new sequences show how much more there is to learn: more than half of P. falciparum's encoding genes still have no known function.

Basic research is also needed to stay ahead of drug resistance in the parasite and insecticide resistance in mosquitoes, and to get a better understanding of natural infection in humans. One surprise from $P$. falciparum's genome is evidence that it evades the human immune system mainly by genomic and gene-expression diversity. Plasmodium seems to have different metabolic and physiological states, and can reprogram its gene expression. These findings could alter the way researchers think about both drug and vaccine development.

The malaria drug and vaccine pipelines are healthier now than they have been for decades, but they are in urgent need of new candidates and approaches. So it was welcome news when the Bill \& Melinda Gates Foundation, already the largest donor in malaria research, announced at the UN summit that it would spend US\$168 million to develop next-generation malaria vaccines. Moreover, this initiative will include early-stage laboratory research - most of the Gates Foundation's funding has so far focused on translational and clinical research.

Many scientists would like to see the foundation fund even more basic research, but this cannot be the foundation's responsibility alone. Its support of translational work has
"The malaria drug and vaccine pipelines are healthier now than they have been for decades." rejuvenated the field over the past decade, and has helped get tools into the field. In the process, the malaria research community has become excessively and undesirably dependent on this one entity. Other research organizations would do well to step up to the plate and match the Gates Foundation's spending with their own basicresearch funds. That would also go some way to addressing what scientists say is an unfortunate consequence of the emphasis on translational research: that scientists entering malaria research are less likely to choose basic science.

Any massive increase in research funding means that the malaria community must think about how to coordinate research across funding agencies. It is encouraging that the main research funders and scientists are to sit down as a group - called MalERA - over the next year to thrash out a research agenda for eradication. One lesson of the malaria and human genome projects is that consortia are a key route to delivery, focusing resources wisely, and avoiding duplication and excessive bureaucracy. It is also essential that international research recognizes the maturity of the malaria research community in the poorer countries where the disease is endemic - they should be on board as equals and not, as is too often the case, afterthoughts.

\section{The Red List still matters}

\section{And the IUCN has more to offer than just data on the nearly extinct.}

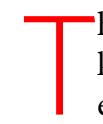

he International Union for Conservation of Nature, better known as the IUCN, is officially venerable. At 60 , it is the oldest global conservation organization. Indeed, its best-known product - the Red List, a compendium of species threatened with extinction - may seem a bit outdated in 2008. After all, the lesson of ecology is that species don't exist in isolation. They evolve and persist because of their relationships with all the other species around them. Conservationists these days usually talk about ecosystems as the units of interest, rather than species.

This trend towards broader thinking has not been lost on the IUCN. This week in Barcelona, Spain, the union is holding one of its four-yearly meetings. On the agenda is the release of the latest version of the Red List, which the union has been keeping since 1963, and which now covers nearly 45,000 species. But the union has also 